\title{
Build Innovation through Organizational Learning Capability
}

\author{
Dr. Abdulmunem Alshehhia *, Prof. Wathiq Mansoor ${ }^{b}$. \\ ${ }^{a}$ Dubai Business School, University of Dubai, United Arab Emirates, a.s.alshehhi@gmail.com \\ ${ }^{b}$ Dubai Business School, University of Dubai, Dubai, United Arab Emirates, gbekele@ud.ac.ae \\ *Corresponding author.
}

Received: 25 Septembre 2018, accepted: 8 Octobre 2018, published: 9 February 2019

\begin{abstract}
This research paper aims to explain the relationship between Organizational Learning (OL), and Organization Innovation (OI). The Author has used analysis of the related literatures to have deep understanding of the subject. This research offers personal mastery, systems thinking and team learning as organizational Learning Capability that will help the entity to have an innovation.
\end{abstract}

Keywords: Organization Learning Organizational Innovation.

JEL codes:

\section{INTRODUCTION}

This paper presents the concepts of OL capability, and how it works to build OI. The focus is on OL in entities and how it affects the employees. The work environment in many government entities is traditional, and entities may not use systematic learning systems with all employees.

The concept of $\mathrm{OL}$ is especially observed in relation to the pertinence (Falconer 2006). It helps organizations to become LO through learning activities within organizations (Small and Irvine 2006). OL is important for innovative culture (Janiunaite and Petraite 2012). OL refers to existing processes while an LO is an ideal form of organization (Örtenblad 2001).

\section{ORGANIZATIONAL LEARNING}

It is necessary to understand what the learning is? $\mathrm{OL}$ is obtaining knowledge or skill through process. The meaning of learning is currently expanding. It covers a better capability to process and create new information that develops humanity (Martha 1994).

Definitions of OL are diverse and are based on the researcher's views and how the concept is defined in research field. OL disciplines can be different, but the definition focuses on how and what organizations learn. OL can be defined as a process that happens across individual, group, and organizational analysis. It can include cognitive, social, and political dynamics (Steil 2015). In other words, it is an organizational procedure of learning through individuals, groups, teams, communities, and the organization itself (Joseph, Firestone and McElroy 2004).

According to Argyris and Schon, OL occurs when individuals learn how to correct their errors after detecting the difference between actual and expected results within organizations. OL works to restructure their tasks and develops strategies to obtain actual results as expected. Therefore, OL will enhance innovation within organizations (Argyris and Schon 1996). $\mathrm{OL}$ is the sum of individuals' capability to learn and influence others. Therefore, an organizational environment can be moved from reactive to proactive. $\mathrm{OL}$ is a process that is built on collectiveness and connected interaction to enable 
meanings to be easily reached. Learning occurs when information is combined with existing knowledge to construct and reconstruct new knowledge (Boateng 2011).

Generally, OL is continuous process of learning through organizations to build learning organizations (Alshehhi and Jasimuddin 2016). Individual learning, team learning, and systems thinking build the LOs that create productive OL mechanisms (Roland 2006).

\subsection{Organizational Learning mechanisms}

An OL capability is a technique focusing on processing learning. It provides processes and procedures to encourage employees to participate and develop skills that lead to improve the innovation of the entity. Individual learning, team learning, and systems thinking can build OL. The following will explain in more details the OL capability:

\subsection{Personal mastery}

Personal mastery is "a set of specific principles and practices that enables a person to learn, create a personal vision, and view the world objectively" (S. Peter 2003- 2016). It is also directed by principles such as purpose, vision, belief, commitment, and knowing oneself (Brendan 2016).

In making the inextricable link between individual learning and $\mathrm{OL}$, people with high levels of personal mastery continually increase their capability to create the results in life they truly seek. From their quest for continual learning comes the spirit of the LO (Rosemary 1996).

Giasemi (2004) has defined personal mastery as a "personal vision and values, strong sense of reality, understanding the value of competency and ability to move from competence to capability".

Personal mastery is continuous engagement of learning and reflection activities to achieve personal growth and continual learning to bridge the gap between the current reality and the desired future.

\subsubsection{Systems thinking}

"System thinking is the recognition of where and when actions and changes in structures can evoke lasting improvements": OL is an important example of actions based on systems thinking. Indeed, when change happens in a feedback response, it means that learning is happening (Montuori 2000).

Systems thinking involves ensuring that an organization has connectivity, dissipation, and emergence. Also, systems thinking supports the view of organizations. Management considers the different needs and abilities of employees during lesson plan development. However, if knowledge practices have changed, management will consider the impact on their results. In dealing with an employee discipline problem, management will consider the impact on other faculties.

\section{2..1.3 Team learning}

Learning teams are an important part of an LO: "Team learning is expressed through interaction processes between team members, during which they organize and integrate interdependent acts or input through cognitive, verbal and behavioral activities to organize team work effectively and create valuable team output" (Elisabeth, et al. 2015).

Individual learning eventually transfers through group processes into institutionalized organizational knowledge: "The new interpreted knowledge is integrated into the groups' and organizations' existing knowledge and becomes institutionalized" (Sandra and Marie-Joe 2010). Network participation is a good internal incentive for emergent learning behavior. The group's members can offer fascinating input when the new team recreates (Sandra and Marie-Joe 2010).

As an internal stimulus for emergent learning behavior, team learning happens through employees' network participation, as they spend time building trust and asking for other views, as well as using team activities in faculty professional development activities. 


\section{OEGANIZATIONAL LEARNING AND INNOVATION}

There are many dimensions of OL: openness to new ideas, psychological safety, team orientation, information collection, knowledge sharing and integration, education and training, experimentation, and the leadership that reinforces learning. These dimensions have positive relationships perceptual innovation (Wencang, Huajing and Xuli 2015).

Popper and Lipshitz (2000) discussed the differences between individual learning and OL. But this study also discussed the similarities at the same time and the different mechanisms used to convert information into actionable knowledge at different systemic stages. Also, it discussed the conditions that promote productive OL, OL feasibility, and the relationship between $\mathrm{OL}$ and LOs. The article states five values that make OL mechanisms productive if they are applied in a suitable organizational culture: 1) continuous learning, 2) valid information, 3) transparency, 4) issue orientation, and 5) accountability (Popper and Lipshitz 2000). The study depended on qualitative research methodology only. Brigita and Monika (2012) found OL to be an important element of innovative culture. The article posed some questions regarding OL:

What features of OL prevail in profit and non-profit organizations? What different (and to what extent different) mechanisms (tools) of innovation management would enable OL in organizations that are of different types and belong to different sectors, and are characterized by different features of OL? (Janiunaite and Petraite 2012)

The techniques of managing the knowledge have an indirect positive effect on financial performance through increased innovation performance. Consequently, OL will improve innovation in organizations (Argyris and Schon 1996).

Senge, the author of The Fifth Discipline and the founder of the Center for Organizational Learning, reflected on his experience, knowledge, and education in his book. In fact, the book was very useful for this research as it showed the practices of LOs through five disciplines (systems thinking, personal mastery, mental models, building shared vision, and team learning). Each was described in depth (Peter 1990).

Organizations aspiring to excellence should have different and more holistic focus as compared to organizations aspiring only to performance (Job and Sanghamitra 2010). Wencang, Huajing and Xuli (2015) developed a framework for studying $\mathrm{OL}$ and the influences of $\mathrm{OL}$ on innovation and financial performance inside organizations. The results showed a positive association between $\mathrm{OL}$ dimensions and performance of organizations. There is also a primary positive relationship between learning ability and OP (Wencang, Huajing and Xuli 2015).

Innovation can be technological and non-technological through process of creating products or services from inventions (Van de Ven and Angle 1989). "The learning organization culture was found to have a significantly stronger relationship with innovation" (Meriam 2005). The work environment has a great effect in terms of facilitators or inhibitors of learning when the organization considers learning. (Sluis 2004). There is a characteristic European tradition in innovation in work organization. The European roots of OL. Thus, the European Ol tradition developing employee's participation and human resourcefulness could be constructed as OL (Nyhan, et al. 2004). However, the ability to innovate in management and process depends on the organization's ability in learning (Hong and Kuo 1999).

\section{CONCLUSIONS}

The researcher has defined OL capability as a continuous process of learning throughout organizations. OL can help organizations to easily involved in any initiative by building cadres who are able to lead them towards more innovation.

There is a relationship between OL and Innovation which will need further study. Husseina et al. (2014) proposed that LO culture has a direct influence on OL and organizational innovativeness, which may lead to the success of organizations in the long term (Husseina, et al. 2014). OL capability (systems thinking, personal mastery, and team learning) predict that, as organizations can increase their OL. The probability of achieving high innovation shall increase significantly. However, personal mastery, systems thinking, and team learning are required more studies to understand the level of relationship and their effects on the OI separately. 


\section{REFERENCES}

Alshehhi, Abdulmunem, and Sajjad Jasimuddin . 2016. "The Notion of Organization Knowledge Systems." International Journal of Business Administration and Management Research 24 - 29.

Argyris, Chris, and Donald Schon. 1996. Organizational Learning: A Theory Of Action Perspective. MA: Addison-Wesley.

Boateng, Richard. 2011. "Do organizations learn when employees learn: the link between individual and organizational learning." An International Journal 6-9.

Brendan, Baker. 2016. What is Personal Mastery - A Look Into Personal Development From a New Perspective. Accessed Oct 17th, 2016. http://www.startofhappiness.com/what-is-personal-mastery/.

Cahill, Dennis. 1997. "The "real world" as classroom: the learning organization and innovation"." The Learning Organization 106-108.

Elisabeth, Raes, Boon Anne, Kyndt Eva, and Doc Filip. 2015. "Measuring team learning behaviours through observing verbal team interaction." Journal of Workplace Learning 476 - 500.

Falconer, Liz. 2006. "Organizational learning, tacit information, and e-learning: a review." The Learning Organization 140151.

Giasemi, Vavoula. 2004. "KLeOS: A knowledge and learning orgnisation system in support of lifelong learning." A thesis submitted to The University of Birmingham for the degree of DOCTOR OF PHILOSOPHY, Birmingham.

Hong, Jon-Chao, and Chia-Ling Kuo. 1999. "Knowledge management in the learning organization." Leadership \& Organization Development Journal 207-215.

Husseina, Norashikin, Amnah Mohamadb, Fauziah Noordina, and Noormala Ishak. 2014. "Learning Organization and its Effect on Organizational Performance and Organizational Innovativeness: A Proposed Framework for Malaysian Public Institutions of Higher Education." Science Direct. Accessed August 19, 2016. http://ac.els-cdn.com/.

Janiunaite, Brigita, and Monika Petraite. 2012. "Organizational Learning for Innovation: Challenges for Different Organizations Management." European Conference on Knowledge Management. Kidmore End: Academic Conferences International Limited.

Job, P. Antony, and Bhattacharyya Sanghamitra. 2010. "Measuring organizational performance and organizational excellence of SMEs - Part 2: an empirical study on SMEs in India." Measuring Business Excellence 42-52.

Joseph, Firestone, and McElroy. 2004. "Organizational learning and knowledge management: the relationship." The Learning Organization 177-184.

Martha, G. White. 1994. "Creativity and the Learning Culture." The Learning Organization 4-5.

Meriam Ismail. 2005. "Creative climate and learning organization factors: their contribution towards." Leadership \& Organization Development Journal 639-654.

Montuori. 2000. "Organizational longevity - Integrating systems thinking, learning and conceptual complexity." Journal of Organizational Change Management 61 - 73.

Nyhan, Barry, Peter Cressey, Massimo Tomassini, Michael Kelleher, and Rob Poell. 2004. "European perspectives on the learning organisation." Journal of European Industrial Training 67-92.

Örtenblad, Anders. 2001. "On differences between organizational learning and learning organization." The Learning Organization 125-133.

Peter, Senge. 2003- 2016. Personal Mastery and Peter Senge: Definition \& Examples. Accessed Oct 17 th, 2016. http://study.com/academy/lesson/personal-mastery-and-peter-senge-definition-examples-quiz.html.

Popper, Micha, and Raanan Lipshitz. 2000. Organizational learning: mechanisms, culture, and feasibility. Thousand Oaks, June.

Roland, Yeo K. 2006. "Development and Learning in Organizations." An International Journal 10-12.

Rosemary, Hill. 1996. "A measure of the learning organization." Industrial and Commercial Training 19 - 25.

Sandra, Fisser, and lle Browaeys Marie-Joe. 2010. "Team learning on the edge of chaos." The Learning organization 58 68.

Sluis, Lidewey. 2004. "'Designing the workplace for learning and innovation: Organizational factors affecting learning and innovation"." Development and Learning in Organizations: An International Journal 10-13,

Small, Adrian, and Paul Irvine. 2006. "Towards a framework for organizational learning." The Learning Organization 276299.

Steil, Jane Lucia. 2015. "Organizational learning and power dynamics: a study in a Brazilian University." The Learning Organization 115-130.

Van de Ven, and Angle. 1989. Research on the Management of Innovation: The Minnesota Studies. New York: Harper \& Row.

Wencang, Zhou, Hu Huajing, and Shi Xuli. 2015. "Does organizational learning lead to higher firm performance?" The Learning Organization 271-288. 